\title{
The Development of Cross-Institutional Senior Capstone Design Project Col- laboration - A Pilot Project
}

\section{Dr. Nikhil Gupta, Florida State University}

Nikhil Gupta received his Bachelor of Technology degree from Y.M.C.A. Institute of Technology, Haryana, India in 2008, Master of Science degree from North Dakota State University, Fargo, ND, in 2010, and $\mathrm{Ph} . \mathrm{D}$ from Florida State University, Tallahassee, FL, in 2014, all in Mechanical Engineering. He is currently an Adjunct Professor teaching Senior Design in the Department of Mechanical Engineering. He is also serving as Postdoctoral Research Associate at Center of Intelligent Systems, Control, and Robotics (CISCOR) at Florida State University. His research interests are primarily in the areas of dynamic system modeling, intelligent control, autonomous mobile wheeled and legged robotics, dynamic motion planning, and mechatronics.

\section{Dr. Matthew James Jensen, Florida Institute of Technology}

Dr. Matthew J. Jensen received his bachelor's degree in Mechanical Engineering from Rose-Hulman Institute of Technology in 2006. Matthew received his doctorate from Clemson University in 2011 in Mechanical Engineering, focused primarily on automotive control systems and dynamics. During his graduate studies, Matthew was awarded the Department of Mechanical Engineering Endowed Teaching Fellowship. He is currently an Assistant Professor of Mechanical Engineering and the ProTrack Co-Op Coordinator at Florida Institute of Technology. His research interests include applications in automotive/transportation safety, electro-mechanical systems, data analysis strategies and techniques, dynamic modeling, and engineering education.

\section{Dr. Chiang Shih, Florida A\&M University/Florida State University}

Dr. Chiang Shih is a Professor of Mechanical Engineering Department, FAMU-FSU College of Engineering, Florida State University. He received his Ph.D. degree from the Aerospace Engineering Department at the University of Southern California in 1988. He has served as the department Chair from 2002 until 2011 and is currently the Director of the Aeropropulsion, Mechatronics and Energy Center established in 2012. He is the coordinator of the ME Senior Capstone Design Curriculum and the dual degree B.S.-M.S. program. 


\title{
The Development of Cross-Institutional Senior Capstone Design Project Collaboration - A Pilot Project
}

\begin{abstract}
For years, engineers in industry have collaborated in teams with colleagues who are separated geographically. The accelerating pace of the globalization of design makes long-distance communication and project management necessary skill sets for engineers since many companies now operate internationally. Although the concept of a virtual design team is not new, it has not been widely adopted in engineering curriculum due to many challenges including: inadequate resource allocation, lack of instructors with virtual design experience, mismatched project course structures between schools, and the difficulty to sustain support to overcome coordination obstacles. In this paper, we will outline preliminary efforts in developing such a crossinstitutional collaborative program between two engineering programs i.e., Mechanical Engineering department at FAMU-FSU College of Engineering, Tallahassee, Florida and Mechanical and Aerospace Engineering department at the Florida Institute of Engineering, Melbourne, Florida. Both programs have strong capstone design curriculum aiming to introduce the students to the real-world engineering design process through the participation in externally funded, hands-on design projects. Students are introduced to the industrial design process by forming cohesive teams where they interact among themselves, with industry sponsors, faculty advisors, and, sometimes, with multidisciplinary members outside engineering schools.

Over the years, Department of Mechanical Engineering at the FAMU-FSU College of Engineering has increased its multidisciplinary projects such that its students are required to collaborate with various engineering and non-engineering programs and, for the past few years, it has expanded the collaboration to a few international universities. The department's past experience with the multidisciplinary approach shows that such projects can leverage on the complementary skills and disciplinary expertise of individuals and institutions so that effective partnership can form to provide inspirational learning experience for all participants.
\end{abstract}

Florida Institute of Technology program has a similar senior design model, spanning a total of three semesters, a single credit junior design course held in the spring semester, followed by both senior year semesters. Being a smaller school with 14 different engineering disciplines, multidisciplinary senior design projects are commonplace, allowing students from various disciplines to work collaboratively to meet the end requirement(s). Oftentimes, senior design projects are industry-sponsored, although national design competitions are sometimes used as well.

Based on multiple deliberations between design coordinators and program leaders, the programs decided to establish a long-term partnership to develop multi-year cross-institutional senior capstone design projects. Similar to multidisciplinary projects, we expect structured coordination and effective communication will be needed to manage a cross-institutional team. Additionally, the project will utilize a virtual enterprise platform as well as some of the commercially available computational tools for collaborative design. Other challenges such as mismatched course management, team identity, responsibility delegation, and resource allocation might require extra efforts to overcome. Therefore, we have identified a well-defined nation-wide engineering design competition event as the first joint project to initiate the collaboration. A two-year plan 
has been drafted to ensure that student teams will not be overwhelmed by multi-tasks to complete all technical requirements, while mastering skills needed to organize a functional virtual team. This paper will discuss the challenges of executing such a project and how can we transform the pilot program into a sustained collaborative team learning experience beneficial to both programs.

\section{Introduction}

One of the primary outcomes for the engineering education is to train students for conducting engineering design and be a better fit for the industrial needs ${ }^{1,2}$. The accelerating pace of the globalization of design makes long-distance communication and project management necessary skill sets for engineers since many companies now operate internationally. To deliver on the same, engineering school are practicing virtual design process ${ }^{3-5}$ as part of their capstone senior design curriculum. However, the process has not been widely adopted in engineering curriculum due to challenges that includes inadequate resource allocation, lack of instructors with virtual design experience, mismatched project course structures between schools, the difficulty to sustain support to overcome coordination obstacles, etc.

This paper proposes and outlines the preliminary efforts in developing a new model of crossinstitutional collaborative program as a part of capstone senior design course between two engineering programs i.e., Mechanical Engineering department at the FAMU-FSU College of Engineering, Tallahassee, Florida and Mechanical and Aerospace Engineering department at the Florida Institute of Engineering (FIT), Melbourne, Florida, to prepare our students according to the global demand of distributed design process i.e., a design project that have team members located remotely or globally dispersed. The capstone senior design project course is a most important design process for the training of engineering students ${ }^{6-9}$. It provides the opportunity for the students to apply the gained knowledge and skill set in the development of a real design problem within a virtual industrial environment setting. This also helps the students to migrate from an academic environment to an industrial environment.

\section{a) Introduction of Mechanical Engineering Senior Design at FAMU-FSU College of Engineering}

Over a decade Mechanical Engineering capstone senior design course at FAMU-FSU College of Engineering has been going through a lot of improvements. The course has evolved to a greater extent, since its transition to the current two-semester format in 1999 ${ }^{10-13}$. The improvements include involving more external sponsors from industry and research institutions ${ }^{10}$, initiation of international design projects with institutes from Brazil and Romania ${ }^{11}$, and increase in multidisciplinary projects and design competition events while collaborating with other engineering departments ${ }^{12,13}$. At present, about fifty percent of the projects are multidisciplinary and more than eighty percent are Industry-sponsored projects, as shown in Table 1. 
Table 1: List of current projects at Mechanical Engineering Senior Design at FAMU-FSU College of Engineering.

\begin{tabular}{|c|c|c|c|c|c|c|}
\hline $\begin{array}{l}\text { Project } \\
\text { No. }\end{array}$ & Project Description & Sponsor & CEE & ECE & IME & ME \\
\hline 1. & Oleophobic Sealing Solutions & Cummins & & & & $\bar{X}$ \\
\hline 2. & Improving the Range of an Electric Vehicle & Cummins & & $\mathrm{X}$ & & $\mathrm{X}$ \\
\hline 3. & Marine Keel Cooler Optimization Tool & Cummins & & & & $\mathrm{X}$ \\
\hline 4. & High Speed Motor Test Rig & Turbocor & & & & $\mathrm{X}$ \\
\hline 5. & Failure Mode Prediction Analysis & Turbocor & & & & $\mathrm{X}$ \\
\hline 6. & Super Shh - A quitter hair dryer & COE & & & & $\mathrm{X}$ \\
\hline 7. & Personal Hydroelectric Generator & COE & & $\mathrm{X}$ & & $\mathrm{X}$ \\
\hline 8. & $\begin{array}{c}\text { Design an Unmanned Tilt-Rotor Aircraft for } \\
\text { Multi-Mission Application }\end{array}$ & $\begin{array}{l}\text { International } \\
\text { Project }\end{array}$ & & $\mathrm{X}$ & & $\mathrm{X}$ \\
\hline 9. & Autonomous Microalgae Photobioreactor & $\begin{array}{l}\text { International } \\
\text { Project }\end{array}$ & & & & $\mathrm{X}$ \\
\hline 10. & $\begin{array}{c}\text { Managing External Thermal Transients on } \\
\text { Electronic Assemblies }\end{array}$ & $\begin{array}{l}\text { Unison } \\
\text { Industries }\end{array}$ & & & & $\mathrm{X}$ \\
\hline 11. & Robo-Weeder & Orchard Pond & & $\mathrm{X}$ & & $\mathrm{X}$ \\
\hline 12. & $\begin{array}{c}\text { Development of Hammer Blow Test Device to } \\
\text { Simulate Pyroelectric Shock }\end{array}$ & Harris & & & & $\mathrm{X}$ \\
\hline 13. & Development Micro-Gap Measurement Device & $\begin{array}{l}\text { General } \\
\text { Capacitor }\end{array}$ & & & & $\mathrm{X}$ \\
\hline 14. & .decimal Proton Therapy Device Manager & .decimal & & & & $\mathrm{X}$ \\
\hline 15. & Portable Wind Turbine & $\begin{array}{l}\text { David H. } \\
\text { Melvin, Inc. }\end{array}$ & $\mathrm{X}$ & & & $\mathrm{X}$ \\
\hline 16. & Loockheed Martin Target Turning Mechanism & $\begin{array}{l}\text { Lockheed- } \\
\text { Martin }\end{array}$ & & & & $\mathrm{X}$ \\
\hline 17. & $\begin{array}{c}\text { Design an Improved Handheld Dog Grooming } \\
\text { Tool }\end{array}$ & $\begin{array}{l}\text { Engineering To } \\
\text { Go }\end{array}$ & & & & $\mathrm{X}$ \\
\hline 18. & Synthetic Active Aperture Radar Imager & $\begin{array}{l}\text { Northrup } \\
\text { Grumman }\end{array}$ & & $\mathrm{X}$ & & $\mathrm{X}$ \\
\hline 19. & Construction Marking Robot & PSBI & & $\mathrm{X}$ & & $\mathrm{X}$ \\
\hline 20. & $\begin{array}{l}\text { Hans Cycles: Reciprocating Lever } \\
\text { Transmission Bicycle }\end{array}$ & Hans Cycles & & & & $\mathrm{X}$ \\
\hline 21. & $\begin{array}{l}\text { Oceanography Submersible Instrument: Milet- } \\
2\end{array}$ & $\begin{array}{c}\text { Oceanography } \\
\text { Submersible } \\
\text { Instrument }\end{array}$ & & & & $\mathrm{X}$ \\
\hline 22. & Autonomous Vehicle Competition & $\begin{array}{c}\text { Design } \\
\text { Competition }\end{array}$ & & $\mathrm{X}$ & & $\mathrm{X}$ \\
\hline 23. & $\begin{array}{c}\text { Design and Development of Autonomous } \\
\text { Underwater Vehicle (AUV) }\end{array}$ & $\begin{array}{l}\text { Design } \\
\text { Competition }\end{array}$ & & $\mathrm{X}$ & & $\mathrm{X}$ \\
\hline 24. & Vacuum Protected Memory & & & & & $\mathrm{X}$ \\
\hline 25. & Ergonomic Brassiere & IME & & & $\mathrm{X}$ & $\bar{X}$ \\
\hline 26. & Palm Fruit Harvester System & IME & & & $\mathrm{X}$ & $\mathrm{X}$ \\
\hline 27. & Stokes Drifter & ECE & & $\mathrm{X}$ & & $\mathrm{X}$ \\
\hline 28. & Electric Bike Charging System & $\begin{array}{c}\text { Efficient } \\
\text { System, LLC }\end{array}$ & & $\mathrm{X}$ & & $\mathrm{X}$ \\
\hline 29. & Strength Assisting Robot & $\mathrm{COE}$ & & $\mathrm{X}$ & & $\mathrm{X}$ \\
\hline
\end{tabular}

In the capstone senior design course the students are expected to work as a cohesive team member with a given opportunity to become team leader, learn how to communicate effectively 
and efficiently among the team members, peers, and sponsors. The course also emphasizes on acquiring soft skills besides the engineering concepts such as professional code of conduct, report writing, and team management. These skills are critical in todays emerging global economies for a successful engineering career. With this in mind, the purpose of the course is to equip the students with technical and non-technical professional skills that could be implemented on engineering design problems, while working in a global team with different dynamics. For the students, to be successful in the course, they have to develop and sharpen skills in organization, time management, self-discipline, and technical writing, while working as a strong team member.

At the end of the school year, the capstone design course concludes with a one-day review event featuring final presentation and open house. In this review event all teams make oral presentations describing their projects, progress made in the given time, and the results obtained to the audience consists of students, faculty, external sponsors, and panel of judges comprises of Mechanical Engineering Advisory Council (MEAC). The oral presentations are then followed by a poster session where the teams showcase their projects and the actual prototype developed under the project. The annual open house is also integrated with the continuous assessment process to identify any strengths and weaknesses of the curriculum for modifications and improvements. This tightly interwoven relationship between the capstone course, curriculum evaluation, and MEAC participation has served the department well in many fronts: continuous improvement of the capstone course and curriculum, harvesting of relevant projects for the capstone course through strong industrial involvement, and expanded career opportunities for our graduates.

\section{b) Introduction of Florida Institute of Technology’s Senior Design}

Florida Institute of Technology has a fairly traditional capstone design curriculum where all science and engineering majors are required to complete a formal design project at the end of their undergraduate studies. Most programs’ capstone design sequences are two semesters, spanning the entire senior year. However, four programs: aerospace, computer, electrical and mechanical engineering, have a three semester sequence that begins in the spring semester of the junior year. The junior design course is a one-credit course that covers various design methodologies and allows students to determine and begin their capstone design project at the early stages of the design process. During the senior design courses, the students work towards the designing, analyzing, building and testing of their projects. The total capstone design curriculum range from 6-8 credits depending on the program student belongs to. The aforementioned four programs that have a junior design component have a total of 8 credits' capstone design course curriculum.

The capstone design teams have at least one faculty advisor/mentor and oftentimes are additionally advised by a graduate student assistant. The capstone design projects are a mix of industry-sponsored projects, student-proposed projects, national design competitions, and faculty-proposed projects. Funding for projects comes from an endowment provided by a large industry partner of the institution and various donations for the specific projects. 
Due to University B being a smaller private institution with 14 undergraduate majors in the College of Engineering, it is commonplace to have interdisciplinary capstone design teams made up of students from two or more engineering or science majors. Projects are housed in a specific department but capstone design instructors work together on interdisciplinary projects to ensure all requirements for each discipline are met to satisfaction. The cross-institutional design project discussed in this paper is an example of such an interdisciplinary project. To date, no crossinstitution project has been used to fulfill capstone design requirements.

\section{Motivation for Collaboration}

As mentioned earlier, due to the globalization and other engineering developments, it is increasingly more important to introduce engineering students to the engineering design practices with multidisciplinary team members who are located remotely. Department of Mechanical Engineering, at FAMU-FSU College of Engineering, international program experience $^{11}$ of working with several international universities on senior capstone design collaborations has been quite valuable for this initiative. The program integrated the international exchange program between U.S. and Brazil and the capstone design process together. Although, we would like to continue this international design collaboration but due to the end of the sponsored exchange program, such collaboration becomes hard to manage. Also, based on our prior experience, international design components are frequently overlooked when the students have to focus on other aspects such as language, cultural and financial difficulties, and the requisites of the exchange program. In addition, local students who do not participate in the exchange program could not get the full appreciation of the experience.

As a result, we felt the more pragmatic way to immerse more students into the design practice where the part of the team is located remotely, would be to work with other domestic institutions, preferably, with schools that are reasonably close to have face-to-face interactions at least once a semester. This led to a discussion between programs, since they locate in the same state and travel from one school to the other is not too demanding. Additionally, their respective senior design project formats are reasonably compatible while providing some challenges to be discussed later. Finally, Mechanical Engineering design director at FAMU-FSU College of Engineering (author 4) and FIT's Chair (author 3) knows each other for more than 30 years as they were doctoral students in the same school. The last factor is an important factor for the initiation of this effort, since strong personal relationship is useful to guarantee the development of a long-term collaborative program.

After a series of discussions in summer 2015, it was decided to have a two-year pilot project with the intent to establish a sustainable collaborative program to introduce cross-institutional design process to both programs. To achieve this goal, specific key objectives for the pilot project have been laid out that includes: (1) identify a multidisciplinary design project topic suitable for both programs, (2) devise a two-year plan for the design project, (3) develop a protocol for communication, project management and shared responsibilities, (4) setup a realistic project timeline and outcome expectations, and (5) provide learning experience for all students about the importance and challenges of such design process. To achieve the last objective, it is required to create a structured platform engaging all stakeholders with clear defined objectives, effective 
communication, timely assessment and continuous improvements. Admittedly, we have fallen short of the last objective due to the short planning time and lack of support and resources for design coordinators for the additional demands. However, experience gained from the current year will be used to make the improvements in the future towards the pilot program.

We hope that the pilot program will be engender long-term collaboration between two programs while expanding to other interested programs. For example, discussion about establishing this cross-institutional collaboration has already been made with the department Chair of another instate school. The successful implementation of the pilot project might bring more resources through internal and/or external funding to facilitate further expansion of such worthy efforts.

With no doubt in our mind, this endeavor will lead to improvement of professional training of our students for preparing them to function effectively in the new paradigm of engineering enterprise with ever increasing demands of global design and product development process. This will also helps the engineering educators to familiarize themselves with the virtual design practices. We have relied on the learn-by-doing strategy to implement our prior global collaborative projects, frequently in an ad-hoc manner. Therefore, we have not been able to establish a systematic framework to effectively guide the multidisciplinary teams to maximize their learning experience. Hopefully, this pilot project and the subsequent long-term development can better prepare engineering educators to integrate the concepts of virtual team and global design process into the core design curriculum so that more students can be benefitted from the training.

\section{Cross-Institutional Collaborative Program Overview}

Department of Mechanical Engineering's international program experience ${ }^{11}$ at FAMU-FSU College of Engineering, while working with several international universities on capstone design process collaboration has been quite valuable. That's why this cross-institutional collaborative program is started at the capstone design process level. Inclusion of this program in capstone design course curriculum provides a well-established initial infrastructure to carry out the team formation and project development work. A two-year plan has been drafted to ensure that student teams will not be overwhelmed by multi-tasks to complete all technical requirements, while mastering skills needed to organize a functional virtual team.

\section{Program Objectives}

a) Project outline and outcome expectations

The cross-institutional collaborative program is aimed to introduce engineering students to the engineering design practices with multidisciplinary team members who are located remotely. For this a pilot project plan has been setup to help in developing into a sustained collaborative team learning experience beneficial to both programs. The pilot project will help to identify challenges such as mismatched course management, team identity, responsibility delegation, and resource allocation and efforts to overcome them. 
As an outcome of the collaboration, it will provide students the training for long-distance communication and project management, couple of the necessary skill sets required for successful engineering career, since many companies now operate internationally.

b) Multidisciplinary design project

From the past experience, we identify that a well-defined nation-wide engineering design competition event will be a better fit to initiate the collaboration. The use of competition provides excitement to the design process and encourages the teams to excel in the design rather than simply meet the requirements. The goals and rules of the competitions require significant technical depth, but the scale of the projects works well for teams of 4-6 with a moderate budget. The inclusion of national level design competitions requires a multidisciplinary design team formation that may include students from ME, ECE, and CS departments to work together.

c) Multi-disciplinary team selection

Before recruiting the students into the team a clear expectation has been conveyed to them that about half of the team being present off the site with very limited access to them. It has also been conveyed that both program teams have to develop a common prototype that can comply with the competition requirements and the course requirement. Along with this the teams have to fulfill the documentation requirements of the course such as conceptual design report, progress update report, operating manual, etc. with a clear emphasis on crossinstitutional collaboration learning. The selection of the team members is done based on the skill requirement, student's interest, and their grade.

d) Two-year plan for project

In order to not overwhelm the students with the multi-tasks to complete all technical requirements of the project while mastering skills needed to organize a functional virtual team a two-year plan for the pilot project has been drafted. It also helps in passing the learned experience to the successive teams while keeping the project requirement same.

Since FIT's senior design course is three semesters long, a team of junior or sophomore has been proposed with the understanding that the same team or members of the team keep continuing on the project during their capstone senior design project course. Whereas, team at FAMU-FSU College of Engineering will help them to provide the initial senior experience that includes project planning and management concepts learned in their Engineering Design Methods course for the initiation of the project. Later on, during the second year, a new team at FAMU-FSU College of Engineering will overtake the project. The team at FIT will help this new team to bring them to the level where the past team has left. This kind of hand holding model will help the students to learn the importance of teamwork and effective communication. This also helps both programs to have a continuous project work going on while making the collaboration a success. 
e) Project management and communication protocol

One of the major aspects of such collaboration is the project management and communication protocol. In attempt to delineate and resolve issues related to a relatively complex cross-institutional project, we should look into modern industry practices. Collaborative design using virtual tools and processes are practiced in industry, when geographically dispersed teams are involved (Boeing 777 is a prime example ${ }^{14}$ ). However, engineering design curricula does not adequately address these practices. While these approaches can solve many of the issues faced by a geographically dispersed team, they introduce challenges of their own such as availability of the common platform to the entire team, variation in expertise level, etc. These challenges are more pronounced in academia since teams may not have access to same resources. As part of this pilot project, both programs will identify such tools and assess them for possible inclusion into the curriculum.

Effective communication is the most difficult aspect to a multi-team, multi-location design project. Modern communication tools including web-based software have increased the options available and made project meetings and discussions easier. The aim of this collaboration is to increase awareness and train the engineering students about the effective and efficient communication while working on a project with team members often geographically separated. To achieve this aim project management serves the best to lay down the key expectation among the different team members for the success of the project. Along with this a well-defined communication protocol is also required so that students can communicate with each other whenever is required.

For the success of pilot project it has been decided that team will be provided with the freedom to come up with their project management and communication plan. However, each team will be provided with a faculty mentor who will overlook their effort and stay in touch with each other to possibly avoid any misconception and logger jam in the project. For the effective communication, the teams has been provided access to smart rooms that have audio-video conferencing capabilities, white boards for brainstorming session, and projector for presentation practices. Besides this, the teams are encouraged to use third party software such as Skype, Google Hangout, Text Messages App, etc. to communicate swiftly and efficiently. It has also been proposed that during the first semester both teams will meet via audio or video conferencing every week to laydown the foundation of their project i.e. conceptual design selection. Since, during the second semester the development of a real prototype will initiate, the meeting frequency changes to biweekly. This gives both teams ample of time to work on their ideas and then communicate the learning.

f) Student's learning assessment

It is necessary to assess the work of the students involved in the collaborative program in a competitive manner that complies with student teams working on different projects. For that reason the team members will be assessed on the efforts made towards the team collaboration and team involvement along with the other evaluation criteria of the capstone senior design course. Towards the end of the two semesters, teams from both programs are invited to the 
final presentation and open house. Here, the external evaluators while providing the constructive feedback for the project improvement will evaluate the teamwork.

At the end of the semester, students are also required to complete a course evaluation known as "Student Perception of Courses and Instructor". The course evaluation will include specific questions on the team management and communication within the diverse team. The data obtained from this evaluation will be used to assess the pilot program outcome and student learning. Also, both programs use an exit interview for the graduating students to evaluate their experience at the school. This interview will be used for the further assessment of the students experience and the program evaluation. Based on the project evaluation and experience gained from the pilot project, the design process with globally diverse team will be extended to more engineering senior students.

\section{Current Collaborative Efforts}

The two programs have slightly different capstone design program requirements. This had lead to the FIT's team being comprised primarily of juniors, while the FAMU-FSU College of Engineering's team is seniors. For next years project, both teams will be seniors, working on the project for their capstone design course. While the two schools' mechanical engineering capstone design course requirements align fairly closely, the FIT needs to work with the ECE and Computer Science departments. This will require the team to be very deliberate with the documentation of every aspect of the project, in order to meet the capstone requirements of all programs.

\section{a) Project selection}

Department of Mechanical Engineering at FAMU-FSU College of Engineering and FIT identified a well-defined nation-wide engineering design competition, the Intelligent Ground Vehicle Competition $^{15,16}$, as the first joint project to initiate the collaboration. The Intelligent Ground Vehicle Competition (IGVC) has been in existence since 1993 and has included competitors from schools such as: University of Michigan-Ann Arbor, the Georgia Institute of Technology, and Yale University. The competition, as it exists today, consists of an autonomous navigation challenge, a design competition, and an interoperability challenge. The IGVC offers a design experience that is at the very cutting edge of engineering education. It is multidisciplinary, theory-based, hands-on, team implemented, outcome assessed, and based on product realization. It encompasses the very latest technologies impacting industrial development and taps subjects of high interest to students. The competition practice team organization and leadership skill development, and there are even roles for team members from business and engineering management, language and graphic arts, and public relations. Students solicit and interact with industrial sponsors who provide component hardware and advice, and in that way get an inside view of industrial design and opportunities for employment.

This year competition requirement is to have a fully autonomous unmanned ground robotic vehicle must negotiate around an outdoor obstacle course under a prescribed time while 
maintaining a minimum of speed of one mph over a section and a maximum speed limit of five mph, remaining within the lane, negotiating flags and avoiding the obstacles on the course.

\section{Project objectives:}

- Design and build a mobile robotic platform that can perceive the course environment and avoid the obstacles while reaching to the goal destination.

- Develop a line following system to follow the course of the competition.

- Develop a waypoint following system to navigate through the course.

- Develop a wireless emergency stop as per the competition requirement.

- Participate in $24^{\text {th }}$ Annual Intelligent Ground Vehicle Competition at Oakland University in Rochester, Michigan on June 3-6, 2016.

Due to both school's lack of experience with the Intelligent Ground Vehicle Competition, as well as the complicated nature of the collaboration, it was decided that the project would be better treated as a two-year project. This would allow for the first year to be used to learn as much as possible, including the general competition rules and team structure. The goal would be to have the two-school team go to the competition with a viable robot, but one that would most likely have significant room for development. The team (with many returning students) would use their previous experience to improve the multi-institution dynamic and create a unique robot that takes advantage of each school's strengths, while minimizing any weaknesses that may have been exposed.

b) Team formation

FAMU-FSU College of Engineering's team is comprised of a computer engineering, an electrical engineering, and three mechanical engineering majors students with senior standing. The students are taking the capstone senior design course as a requirement of their undergraduate degree. The project is lead by the Department of Mechanical Engineer and provided with a faculty adviser having the expertise in the field of mechatronics. The team is formed on the basis of students' interest, grades, and expertise.

FIT's team is comprised of a computer engineering, electrical engineering, mechanical engineering and computer science majors. Most students are juniors, although one sophomore is also on the team as a volunteer (not currently receiving any course credit). The lead advisor is a mechanical engineering faculty; however, the team also has an electrical engineering advisor and computer science advisor who collaborate with the lead advisor for course requirement activities.

c) Deliverables

In order to assess the teams performance and learning, both teams at FAMU-FSU College of Engineering and FIT are supposed to work coherently and comply with the capstone senior design class deliverable requirements. During the first semester i.e. fall semester, the teams are required to submit reports on Code of Conduct, Needs Assessment, Project Planning and 
Product specification, Conceptual Design, and Interim Design. In the second semester, i.e., spring semester, the teams are required to submit three reports, Operational Manual, report for Manufacturing, Reliability, and Economics, and a final project report. Along with these reports team has to also present periodically and hold staff meetings with the senior design coordinator to make sure they are on the right track.

The Code of Conduct covers the ethical part of the training program. Each member of the both teams are required to sign the Code of Conduct which states the ethical conduct during the process of project development. The next deliverable is to come up with the Needs Assessment, which makes the teams to understand their project and what are they required to do in it. In this exercise both teams explore and study the competition rules and regulation with the design requirements. Based on their understanding the team has to submit a report conveying the constraint and objective of the project and what are they going to focus on as part of their project in the coming two semester.

Once the Needs Assessment has been done, the team has to pair up again and develop a viable project plan and product specification with work break down structure and schedule. For this report generation students uses tools and concept taught to them during their Engineering Design Methods course such as Gantt chart, critical path method, morphological chart, etc. The objective of the report is to make students understand the importance of scheduling and resource allocation before hand and come up with certain milestone. These milestones help the teams to motivate them once they achieve them and convey how far are they in the project.

After the project planning, both teams work separately to come up with initial conceptual design based on the Needs Assessment and Project Planning and Product Specification report. Once they have the initial concepts ready, the team is asked to present their design by the midterm to their peers, mentors, faculty adviser and the course coordinator for constructive feedback. The teams are also asked to submit a report on the same. Towards the end of the semester the team has to provide an interim design report, stating the progress made so far, the final design selected based on the decision matrix, more in details drawing of the concept they are going on to work upon along with discussion of the future work.

In the beginning of the spring semester, the team has to provide an oral presentation on the last semester accomplishments and recent updates with an updated Gantt chart. By this time they are expected to start ordering parts and materials for their prototype. In the second half of the semester students are required to submit an Operational Manual. The manual provides all the necessary details and steps for how to operate the prototype assuming the user do not know or have very limited understanding of the prototype operation. The second report of the semester is on Design Manufacturability, Reliability, and Economics. In this report, assuming the sponsor may want to make the prototype from scratch and want to further develop it, how should one go for it. The team based on their experience from the prototype development has report how they have made changes in their design to make it easy to manufacture. They are also required to report on the reliability of their design based on various analysis performed such as FMEA, FEA, etc., and the cost analysis. As of the final 
report, the team is required to submit a comprehensive report on their project and present on it. This report covers their two semester hard work from needs assessment to interim design and then to the realization of their final prototype.

These deliverables are designed such a way that teams at both programs have to work closely with each other with effective communication and share their ideas. As an important lesson learned from past multidisciplinary design project experience, these deliverables compel the teams to work in both individual team level and combined team level. For example, during the conceptual design development, both teams work separately to come up novice and innovative design ideas and then discuss the merits of each other designs. This gives freedom to each member of the team to be part of the development task. Also, after the interim design report, the work is to be delegated to the individual team members or group of two or three based on their expertise level and understanding.

d) Communication

An important aspect of the success of the cross-collaborative program is the communication between the two teams and among the team members. For effective communication and document sharing a Google Drive folder was created where students can share and edit documents together at any time. Also, the students created a Github site for the sharing of the software code related to the neural network, testing program, sensor fusion, and computational hardware used to execute everything together. Skype and Facetime were also used for videoconferencing with each other (see Figure 1). For internal communication, teams are using a variety of tools for communication. FIT team is using Groupme, a group text messaging group for all team members to instantaneously communicate.

e) Project development and Testing coordination

The current team structures have the FAMU-FSU College of Engineering team taking the lead on the robot structure and powertrain (see Figure 2), while FIT is the lead on sensing and navigation. This results in the physical robot being built at FAMU-FSU College of Engineering, requiring coordination in order to implement and test the FIT portion of the project. With the current plan, the FAMU-FSU College of Engineering team will be shipping a prototype version of the robot to FIT team in order to do the testing of the sensor array and navigation algorithms. While testing is being completed by FIT, FAMU-FSU College of Engineering will be completing the final version of the robot, which will need to be married with the FIT components, followed by final testing of the entire completed robot. 


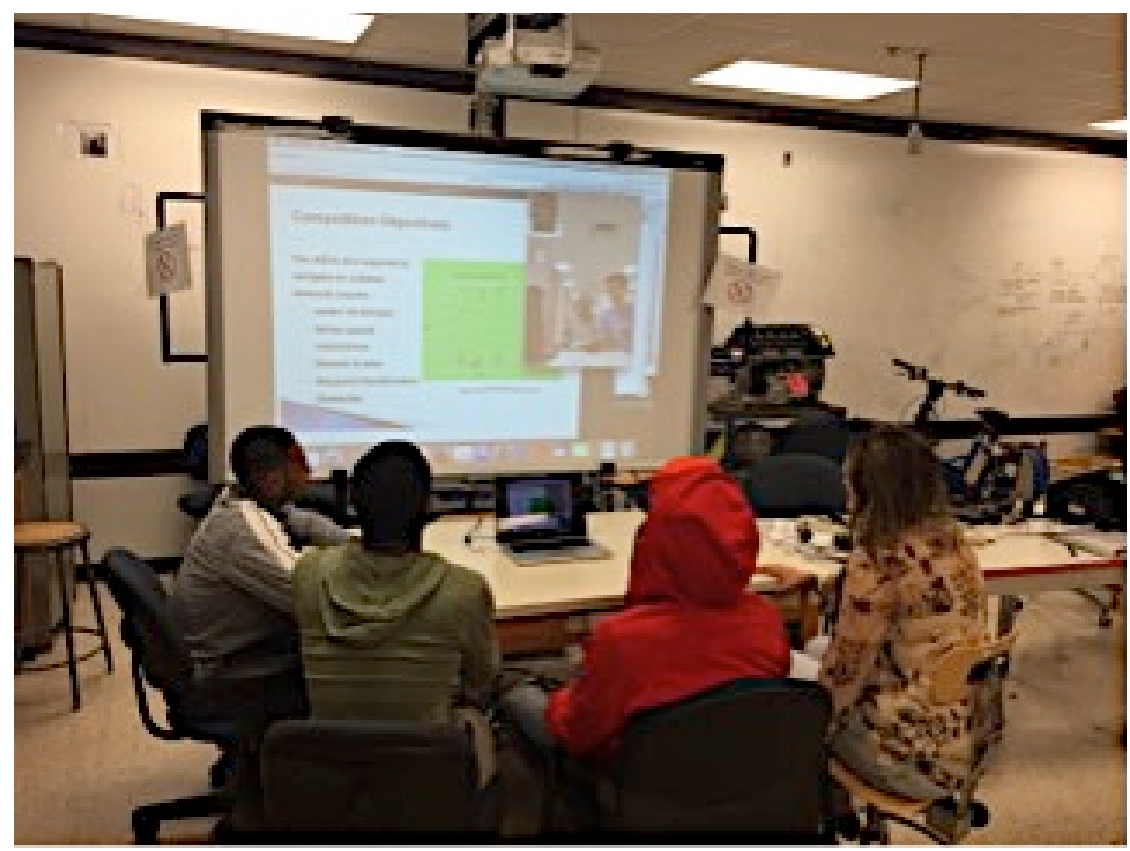

Figure 1: Team at FAMU-FSU College of Engineering having videoconferencing with team at FIT.

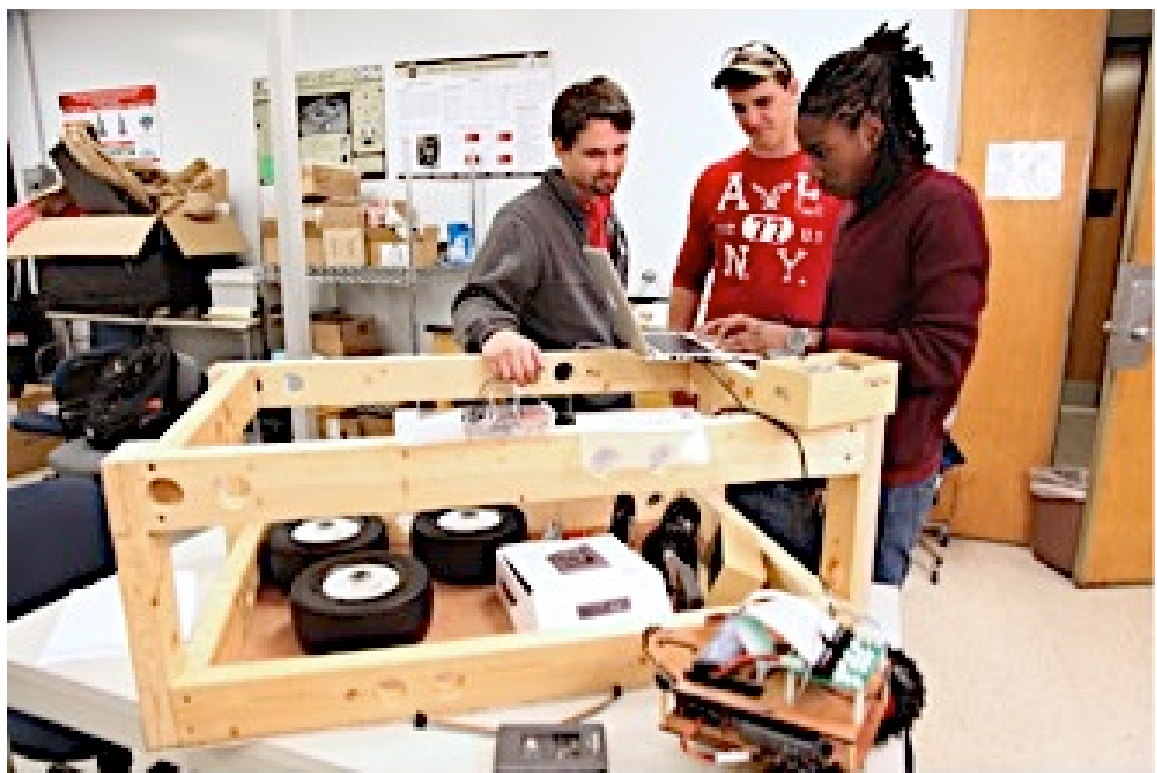

Figure 2: Team at FAMU-FSU College of Engineering working on robot chassis and drivetrain.

\section{f) Software compatibility}

The two programs have different software packages available for their students to utilize. Specifically, the CAD software used at FAMU-FSU College of Engineering is a different package than that used at FIT, so the students have had to find common file types to share, and determine an effective method for task distribution so as to not run into software 
compatibility issues. Likewise, the two teams has different experiences with software programming languages, so the overall system design process had to take into account that the sensing and route planning code must interface with the motor control. A choice of programming language was not as simple as whatever worked best for that one particular task.

\section{Lesson learned/Accomplishment/Challenges}

As mentioned earlier that virtual design process has not been widely adopted in engineering curriculum due to many challenges that includes inadequate resource allocation, lack of instructors with virtual design experience, mismatched project course structures between schools, and the difficulty to sustain support to overcome coordination obstacles. To overcome these challenges we initiated a pilot program for cross-collaboration in developing a senior design project between two relatively local programs (FAMU-FSU College of Engineering and FIT). The project started in Summer 2015 with several meetings to lay down the objectives of it and how it will be managed down the road. After various successful meetings it has been decided that the student project will be a national design competition that will have a well structure requirements and learning element for the students working on it. It has also been decided that the project selected will be stretched to two years so as to not overburden the students and give the course coordinators ample of time to understand the limits of cross-collaboration.

Since, we have relied on the learn-by-doing strategy to implement our prior global collaborative projects, it has been decided that the teams will be given the freedom to lead the way in terms of communication and project management initially, to which our students have done a great job so far. The students incorporated teleconferences, videoconferences, emails, cloud-based shared folders and third party software in order to present their ideas and keep the design process moving forward. It has been realized that regardless of the tool used however, a common time must still be found for live interactions. This project has illustrated the importance of regularly schedule meetings between the two sites. It has also illustrated how difficult it can be to arrange a common time for $10+$ busy team members who many other time commitments. In order to combat this issue, the two teams have begun to plan meeting times much further in advance than they might be used to. Additionally, the team members have realized the value of proper meeting minutes so as to be able to report back to missing team members what was discussed at meetings at a later time.

Again, many issues related to conducting a complex cross-institutional design projects involving geographically dispersed teams can be mitigated through the application of modern industry practices. Collaborative design using virtual tools and processes have been successfully practiced in industry, when geographically dispersed teams are involved. Boeing $777^{14}$ is a prime example where Boeing and Dassault Systems ${ }^{17}$ pioneered the concept of digital mockup to design and model all the parts of the product on a computer. Other great example is the PACE (Partners for the Advancement of Collaborative Engineering Education) program. The program is a partnership between General Motors, Siemens PLM Software, Autodesk, Hewlett Packard and Oracle with a mission to develop the automotive Product Lifecycle Management (PLM) team of the future, by closing the gap between engineering education and practice. These concepts can be 
extended beyond the automotive industries to the capstone design process through the use of Product Lifecycle Management (PLM) software such as PTC Windchill ${ }^{18}$ or Siemens PLM software including NX Cad and Teamcenter ${ }^{19}$. These tools can create a common digital environment to help a dispersed global design team develop a common 3D definition of the product. Many of these platforms, such as PTC, Creo for example, support a Multi-CAD environment allowing different groups to utilize their legacy CAD tools. A pilot project that applies these technologies in the context of an undergraduate senior design program is extremely valuable to delineate challenges associated with geographically dispersed team project and resolve them. This approach can opens a new horizon in engineering design curricula where geographic location is not a limiting factor for collaboration. Depending on the first year progress, such options will be tried and tested during the second year of the pilot project.

With two different universities being involved in this project, questions will arise pertaining to who will fund what aspects of the projects, who will retain overall ownership of the completed project, how any IP generated from the project will be handled, etc. While these issues can be resolved to mutual satisfaction, it does bring up a unique issue that still need to be addressed.

\section{Student Survey, Views, and Testimony}

For the students being part of the autonomous vehicle project is a great experience in many different ways. The multidisciplinary teamwork provided them better understating of various aspects of the project such as mechanical structure, digital control, component selection, etc. It allows the mechanical engineers to work closely with the computer engineers to achieve a common goal while providing some foundation. The students at FIT are mostly juniors who are not currently receiving credit for the project. They are engaged purely due to the passion and motivation to be a part of this unique project and collaboration. They meet approximately 5 hours a week as either a team or sub-team, and put in additional hours on their own to complete their tasks. One of the students on the team quoted that:

"Research was a vast amount of what this project entailed due to the fact that no one person on the team had any prior experience. But through this research we were able to learn how important it is to be knowledgeable and grow as an engineer."

The distributed design program along with the competition provided each member of the team experience to be a well-rounded engineer as it made each member of both teams to step out of his or her comfort zone and learn things outside of their discipline. The following student's quote second this:

"The distance learning by far gave the greatest experience; it presented a real-world situation, because each member working on a project will not always be in the same location so effective communication is essential."

Although there are several learning experiences from this project, it most certainly had its limitations. The lack of resources made available made it difficult to properly test designs before ordering of products. The tight window for fabrication without any prior knowledge of topic 
made it difficult to establish a design suitable for both teams. The lack of communication materials made it difficult to effectively communicate between each school in an interactive fashion. With improvements to these things, this project experience can be made more pleasant and learning. The students found saying that:

"Provided we had access to rapid prototyping and digital testing tool our experience in the project is one that will not be forgotten and will greatly benefit us in the real world."

"The biggest challenge for this project is communication between both teams; in terms of finding a common time that we both are available to discuss the progress of the project and future of the project was extremely tough. We were able to utilize several different methods of telecommunication, such as Skype and conference calling.”

To understand the experience gain by the students during the first year of the pilot program a short survey was performed. All the involved students at each program were asked the following questions.

1. What are the advantages and disadvantages so far to collaborating?

2. What is it like to communicate to an offsite group of people, and what are the difficulties?

3. What techniques are you using to work together (including software, etc.)?

4. How did you go about partitioning tasks between the two teams and how did that affect you onsite?

5. What needs improvement and what are some of your ideas to improve the collaboration (anything from scheduling, prototypes and models, to task partitioning etc.)?

Out of 10 students only 9 responded. Students unanimously stated that the advantage of having a cross-institutional collaboration is sharing the resources while delegating work in an efficient manner. However, due to lack of proper communication the advantage was not exploited to its best. Since, the both team members had different priorities, being a mix of junior and senior year students, finding out a common time for group meeting and discussion was a challenging job. The teams used Groupme, SLACK, SKYPE, Github, and Google Hangout for the meeting and document sharing. The distribution of the task was done based on their strength and available resources. That's why the FAMU-FSU College of Engineering team was delegated with the task of mechanical structure and speed control, whereas FIT team was delegated with the task of development of sensory suite. It is quite evident that FAMU-FSU College of Engineering has state of the art machine shops, whereas FIT has strong computing program. As mentioned earlier, the pilot project was initiated as an adhoc manner and lot was left open for the students. This is something not appreciated by the students and thus strongly suggested to provide a structured requirements for every stakeholder (including the faculty advisers) while stressing heavily on communication requirement. It has also been suggested to have an onsite visit at least once in 3 months to layout the key objectives and the delegation of task. 


\section{Conclusion and Future Work}

With the globalization and other engineering developments, it is increasingly more important to introduce engineering students to the engineering design practices with multidisciplinary team members who are located remotely. One of the solutions to introduce engineering students to such practices is to use virtual design team in capstone senior design course. However, virtual design team concept often do not get adopted well in engineering curriculum due to challenges such as inadequate resource allocation, lack of instructors with virtual design experience and mismatched project course structures between schools. On these lines, this paper proposes and outlines the preliminary efforts in developing a new model of cross-institutional collaborative program between two engineering programs to prepare our students according to the global demand. Both programs have strong capstone design curriculum aiming to introduce the students to the real-world engineering design process through the participation in externally funded, hands-on design projects.

To understand and learn the complications of a cross-institutional collaborative program a pilot project has been initiated in which Annual Intelligent Ground Vehicle competition, a national level design competition was selected as a base project between the two programs. Due to the technical complexity involved and lack of prior knowledge of the design competition, a two-year project plan was laid down. For the first-year plan a multidisciplinary team of seniors was established at FAMU-FSU College of Engineering, whereas Florida Institute of Technology (FIT) team consists of juniors, expected to continue the project in their senior year. In the second year, FIT team will facilitate in bridging the knowledge gap when FAMU-FSU College of Engineering will have a new team of senior students to work on the same project. With the help of the teams and their faculty adviser the design project development and a testing plan was established.

For the success of the design project and the pilot project as well stronger emphasis has been made on the communication protocol. Though the teams are provided with the freedom to come up with their own project management and communication plan, each team is provided with a faculty mentor to vouch for smooth flow of ideas and information sharing between the two teams. For effective and efficient communication access to smart rooms and use of third party software such as Skype, Groupme, etc. is allowed. Teleconferences, videoconferences, emails, and cloud-based shared folders are used as primary source of communication in order to present ideas and keep the design process moving forward. However, based on the survey outcome, it is very evident further emphasis on clear communication is required to have proper project management.

In attempting to delineate and resolve issues related to a relatively complex cross-institutional project, there is a need to look into modern industry practices. Collaborative design using virtual tools and processes are practiced in industry, when geographically dispersed teams are involved. However, engineering design curriculum does not adequately address these practices. Therefore as part of future development of cross-collaboration program such tools and processes will be identified and bring in to use by the students. The other complexity that may come out of such 
collaboration is the ownership and cost sharing. While these issues can be resolved to mutual satisfaction, it does bring up a unique issue that will be addressed in the near future.

\section{References}

1 Pilar Pazos and Nina Magpili. "Facilitating Team Processes in Virtual Team Projects Through a Web-Based Collaboration Tool and Instructional Scaffolds". 2015 ASEE Annual Conference and Exposition, Seattle, Washington, 2015, June. ASEE Conferences, 2015.

2 Hirleman, E. Daniel, Eckhard A. Groll, and Dianne L. Atkinson. "The three axes of engineering education." International Conference on Engineering Education, Coimbra, Portugal, September. 2007.

3 Volkwein, J. Fredericks, et al. "Engineering change: A study of the impact of EC2000." International Journal of Engineering Education 20.3 (2004): 318-328.

4 Beth McGrath, Peter Dominick, Kishore Pochiraju, Souran Manoochehri, Zvi Aronson, George Korfiatis, and Keith Sheppard. "The Role Of Virtual Student Design Teams In Engineering Education For The "New Workplace”". 2004 Annual Conference, Salt Lake City, Utah, 2004, June. ASEE Conferences, 2004.

5 David Wyrick and Adji Cisse. "Virtual Engineering Design Teams". 2009 Annual Conference \& Exposition, Austin, Texas, 2009, June. ASEE Conferences, 2009.

6 Todd, Robert H., et al. "A survey of capstone engineering courses in North America." JOURNAL OF ENGINEERING EDUCATION-WASHINGTON- 84 (1995): 165-174.

7 Dutson, Alan J., et al. "A Review of Literature on Teaching Engineering Design Through Project-Oriented Capstone Courses." Journal of Engineering Education 86.1 (1997): 17-28.

8 Atman, Cynthia J., et al. "Engineering design processes: A comparison of students and expert practitioners." Journal of engineering education 96.4 (2007): 359.

9 Genco, Nicole, Katja Hölttä-Otto, and Carolyn Conner Seepersad. "An experimental investigation of the innovation capabilities of undergraduate engineering students." Journal of Engineering Education 101.1 (2012): 60.

10 Luongo, C. A., and C. Shih. "Senior Design Projects in Mechanical Engineering--A Case Study of Capstone Experience with Strong Industrial Participation." Paper 717 (2006): 18-21.

11 Ordonez, J. C., et al. "An international component to capstone senior design projects." Frontiers in Education Conference, 36th Annual. IEEE, 2006.

12 Waryoba, D., C. A. Luongo, and C. Shih. "Integration of Industrial-Sponsored and Design Competition Projects in the Capstone Design Course." American Society of Engineering Education Southeast Section Conference. 2009.

13 Michael P. Frank, Kamal E. Amin, Okenwa I. Okoli, Sungmoon Jung Ph.D., Robert A. Van Engelen, and Chiang Shih. "Expanding and Improving the Integration of Multidisciplinary Projects in a Capstone Senior Design Course: Experience Gained and Future Plans". 2014 ASEE Annual Conference, Indianapolis, Indiana, 2014, June. ASEE Conferences, 2014.

14 Snyder, CHAULES R., Charles A. Snyder, and Chetan S. Sankar. "Use of information technologies in the process of building the boeing 777." Journal of Information Technology Management 9 (1998): 31-42.

15 Theisen, Bernard L., and Andrew Kosinski. "The 20th annual intelligent ground vehicle competition: building a generation of robotists." IS\&T/SPIE Electronic Imaging. International Society for Optics and Photonics, 2013.

16 The $24^{\text {th }}$ Annual Intelligent Ground Vehicle Competition available online at: http://www.igvc.org/

17 Dassault Systems, available at http://www.3ds.com/about-3ds/

18 PACE program overview, available at http://www.pacepartners.org/files_pub/PACE-Overview.pdf

19 PTC Product Life Cycle Software, available at http://www.ptc.com/product-lifecycle-management

20 Siemens Product Lifecycle Mangement Software, available at http://www.plm.automation.siemens.com/en_us/ 